\title{
Effect of Dopants on Zirconia Stabilization-An X-ray Absorption Study: II, Tetravalent Dopants
}

\author{
Ping $\mathrm{Li}^{\star}$ and I-Wei Chen* \\ Department of Materials Science and Engineering, University of Michigan, Ann Arbor, Michigan 48109-2136
}

James E. Penner-Hahn

Department of Chemistry, University of Michigan, Ann Arbor, Michigan 48109-1055

$\mathrm{X}$-ray absorption spectra at $\mathrm{Zr}-K, \mathrm{Ce}-L_{\mathrm{III}}$, and Ge- $K$ edges in $\mathrm{ZrO}_{2}-\mathrm{CeO}_{2}$ and $\mathrm{ZrO}_{2}-\mathrm{GeO}_{2}$ solid solutions have been measured at $10 \mathrm{~K}$. Both Ce and Ge substitute for $\mathrm{Zr}$ in the cation network, but $\mathrm{CeO}_{8}$ and $\mathrm{GeO}_{4}$ polyhedra are maintained around the dopants. The oversized $\mathrm{CeO}_{8}$ is compressed to a Ce-O distance of $2.30 \AA$, which is smaller than the $2.35 \AA$ seen in fluorite-type $\mathrm{CeO}_{2}$. Meanwhile, the distortion of the $\mathrm{Zr}$-cation network is increased and the tetragonality is reduced. The undersized $\mathrm{Ge}$ has a $\mathrm{Ge}-\mathrm{O}$ distance of $1.80 \AA$, which is much shorter than the $\mathrm{Zr}-\mathrm{O}_{\mathrm{I}}$ distance of $2.10 \AA$. A strong tendency for $\mathrm{Ge}-\mathrm{Zr}$ ordering in tetragonal solid solutions into locally scheelite-like clusters, even within the solubility limit, is observed. This results in an increase in the tetragonality and a decrease in the distortion of the cation network. Despite the opposite effects on tetragonality, both Ce and Ge doping can stabilize tetragonal zirconia albeit via different mechanisms. The structural origin of the cubic phase is also elucidated.

\section{Introduction}

$\mathbf{I}^{\mathrm{T}}$ IS well known that aliovalent dopants, such as $\mathrm{Y}^{3+}, \mathrm{Sc}^{3+}$, $\mathrm{Ca}^{2+}$, and $\mathrm{Mg}^{2+}$, can stabilize high-temperature polymorphs of zirconia. Oxygen vacancies, introduced by these dopants for charge compensation, have been shown to play an important role in stabilizing the cubic and tetragonal structures. ${ }^{1-3}$ Tetravalent dopants ( $\mathrm{Si}, \mathrm{Ge}, \mathrm{Ti}, \mathrm{Sn}, \mathrm{Ce}, \mathrm{Th}$, and $\mathrm{U}$ ) do not create anion vacancies, yet they still stabilize tetragonal zirconia against monoclinic distortion. ${ }^{4}$ The origin of this stability is not understood and is the subject of this paper.

Zirconia solid solutions with tetravalent oxides, including $\mathrm{ZrO}_{2}-\mathrm{CeO}_{2},{ }^{5,6} \mathrm{ZrO}_{2}-\mathrm{TiO}_{2}{ }^{7,8}$ and $\mathrm{ZrO}_{2}-\mathrm{GeO}_{2}{ }^{4,9}$ have been studied in some detail. Of these, $\mathrm{Ce}^{4+}$ is an oversized dopant and $\mathrm{Ti}^{4+}$ and $\mathrm{Ge}^{4+}$ are undersized. Although their tetragonal-tomonoclinic transformation temperatures all decrease with increasing dopant concentration, ${ }^{9}$ the crystallographic variations are dependent on dopant sizes. The $c / a$ ratio of the tetragonal form decreases with increasing $\mathrm{Ce}^{4+}$ content and a cubic phase forms at high Ce concentrations. ${ }^{5,6}$ This behavior is similar to that observed in trivalent-cation-doped zirconia systems. On the other hand, the $c / a$ ratio increases with increasing $\mathrm{Ti}^{4+}$ and $\mathrm{Ge}^{4+}$ content and these tetragonal solid solutions do not

W. White contributing editor

\footnotetext{
Manuscript No. 194507. Received June 3, 1993; approved December 13, 1993.

Supported by the U.S. National Science Foundation under Grant No. DMR-91-19598. SSRL is operated by the Department of Energy, Office of Basic Energy Sciences, Division of Chemical Sciences, with additional support from the NIH, Biomedical Resource Technology Program, Division of Research Resources and the Department of Energy, Office of Health and Environmental Research.

"Member, American Ceramic Society.
}

approach the cubic form..$^{4-10}$ The phase diagrams of these systems are also dependent on dopant sizes. The tetragonal solid solution region in $\mathrm{ZrO}_{2}-\mathrm{CeO}_{2}^{5}$ is much wider than those in $\mathrm{ZrO}_{2}-\mathrm{MO}$ and $\mathrm{ZrO}_{2}-\mathrm{M}_{2} \mathrm{O}_{3}$ systems. ${ }^{\text {I }}$ Similar observations hold in the $\mathrm{ZrO}_{2}-\mathrm{UO}_{2}$ and $\mathrm{ZrO}_{2}-\mathrm{ThO}_{2}$ systems. ${ }^{12-13}$ With undersized dopants, a series of $\mathrm{ABO}_{4}$-type ordered compounds is found. ${ }^{4}$ These include $\mathrm{ZrTiO}_{4}$, an $\alpha-\mathrm{PbO}_{2}$-like structure with a fairly narrow composition range; $\mathrm{ZrGeO}_{4}$, a scheelite structure with a broader composition range; and $\mathrm{Zr}_{3} \mathrm{GeO}_{8}$, also a scheelite-like structure with a similarly broad composition range. ${ }^{9}$ In addition, $\mathrm{ZrO}_{2}-\mathrm{SnO}_{2}$ forms $\mathrm{ZrSnO}_{4}$, which is isomorphic with $\mathrm{ZrTiO}_{4}$, and $\mathrm{ZrO}_{2}-\mathrm{SiO}_{2}$ forms a zircon structure, $\mathrm{ZrSiO}_{4}{ }^{4}$ This tendency reflects different energetics of the tetragonal solid solution with undersized tetravalent cations and could be related to their stabilization effect.

Although the crystallography of the ordered structures has been well established, ${ }^{14.15}$ the distribution and local atomic environments of the dopants in the solid solution range are not known. From our previous EXAFS studies of trivalent-cationdoped zirconia systems, ${ }^{3}$ we can reasonably expect that the dopant distribution may not be random and that the dopant local structure may not be the same as the host $\mathrm{Zr}$ local structure. These aspects may account for the variations in tetragonality and stabilization for the different dopant cations and form the focus of the present study. $\mathrm{Ce}^{4+}$ and $\mathrm{Ge}^{4+}$ were chosen as dopants since the former is the most commonly used oversized tetravalent stabilizer and the latter is the most effective undersized tetravalent dopant for stabilizing tetragonal zirconia at room temperature. The new data on these cations will be considered in conjunction with our previous findings for trivalent cations ${ }^{3}$ to address the interconnections among phase stability, tetragonality, oxygen vacancy, and dopant chemistry. Further introduction to the background of zirconia stability and a complete list of references to the previous EXAFS studies on zirconia were given previously.

\section{Experimental Procedure}

\section{(I) Materials}

The powder preparation techniques used in our study have been described previously. ${ }^{16}$ In the present work, ultrafine powders of zirconia with 5,10 and $15 \mathrm{~mol}^{\circ} \mathrm{GeO}_{2}$ were synthesized by coprecipitation using zirconium oxychloride and germanium ethoxide as starting materials, followed by drying at $250^{\circ} \mathrm{C}$ and calcination at $1000^{\circ} \mathrm{C}$ in air. These samples are designated $5 \mathrm{Ge} 10,10 \mathrm{Ge} 10$, and $15 \mathrm{Ge} 10$, respectively. Similarly, $\mathrm{ZrO}_{2}$ powders with 11,16 and $25 \mathrm{~mol}_{\%} \mathrm{CeO}_{2}$ were coprecipitated using cerium(III) nitrate as the source of Ce. These powders were calcined first at $650^{\circ} \mathrm{C}$ and then oxidized at $850^{\circ} \mathrm{C}$ in a flowing $\mathrm{O}_{2}$ atmosphere to prevent the formation of $\mathrm{Ce}^{3+}$. They are designated $11 \mathrm{Ce} 08,16 \mathrm{Ce} 08$, and $25 \mathrm{Ce} 08$, respectively. 
Phase identification and lattice constant measurements were made by X-ray diffraction (XRD). The results are summarized in Table I. The XRD patterns show typical tetragonal zirconia peaks for the 5- and 10-mol\%-Ge-doped samples. At $15 \mathrm{~mol} \%$ $\mathrm{GeO}_{2}$, a distorted tetragonal pattern was found with a broadened second peak in all of the tetragonal doublets (Fig. 1). According to Lefèvre, ${ }^{9}$ this composition contains a mixture of tetragonal $\mathrm{Zr}(\mathrm{Ge}) \mathrm{O}_{2}$ solid solution and $\mathrm{Zr}_{3} \mathrm{GeO}_{8}$. These phases became more fully separated at higher calcination temperatures. Since the two phases have essentially identical $c$-spacing and only slightly different $a$-spacing, a mixture of the two patterns gives rise to the broad (200), (220), (131), and (400) reflections and the sharp (002), (202), (113), and (004) reflections. This explains the XRD patterns observed at $15 \mathrm{~mol} \% \mathrm{GeO}_{2}$. A small amount of monoclinic zirconia was also observed in $15 \mathrm{Ge} 10$ but not in the $5 \mathrm{Ge} 10$ and $10 \mathrm{Ge} 10$ samples. This probably results from transformation of the tetragonal phase due to the larger powder particle size in $15 \mathrm{Ge} 10$. (Ge, like $\mathrm{Si}$, is likely to promote coarsening by forming a glassy phase.)

Broad XRD peaks were observed for all of the Ce-doped samples calcined at $850^{\circ} \mathrm{C}$ due to their small crystallite sizes. The powders, calcined again at $1300^{\circ} \mathrm{C}$, are single tetragonal phase for 11 and $16 \mathrm{~mol} \% \mathrm{CeO}_{2}-\mathrm{ZrO}_{2}$, while $25 \mathrm{~mol} \% \mathrm{CeO}_{2}-$ $\mathrm{ZrO}_{2}$ powder contains a small amount of cubic form (Fig. 2). The results are consistent with the current phase diagram. ${ }^{5}$ Since the amount of cubic phase was small, we used the measured lattice parameters without correction.

For tetragonal zirconia, both lattice parameters increase but the $c / a$ ratio decreases with increasing $\mathrm{Ce}$ concentration. In contrast, $c$ increases and $a$ decreases with increasing Ge concentration, causing the $c / a$ ratio to increase. The apparent increase in the $c / a$ ratio is larger than expected for the $15 \mathrm{~mol} \%$ Ge sample because of the higher $c / a$ ratio in $\mathrm{Zr}_{3} \mathrm{GeO}_{8}$. In general, our lattice constant results are in good agreement with previous studies." For later reference, the structures of $t-\mathrm{ZrO}_{2}$, $\mathrm{Zr}_{3} \mathrm{GeO}_{8}, \mathrm{ZrGeO}_{4}, \mathrm{GeO}_{2}$, and $\mathrm{CeO}_{2}$ according to published diffraction data are given in Table II..$^{24.17 .18}$

Table I. Lattice Constants of Ce- and Ge-Doped Tetragonal Zirconia

\begin{tabular}{cccc}
\hline Composition & $a(\AA)$ & $c(\AA)$ & $c / a$ \\
\hline $11 \mathrm{~mol} \% \mathrm{CeO}_{2}$ & 5.122 & 5.218 & 1.019 \\
$16 \mathrm{~mol} \% \mathrm{CeO}_{2}$ & 5.139 & 5.231 & 1.018 \\
$25 \mathrm{~mol}_{2} \mathrm{CeO}_{2}$ & 5.169 & 5.253 & 1.016 \\
$5 \mathrm{~mol} \% \mathrm{GeO}_{2}$ & 5.076 & 5.187 & 1.022 \\
$10 \mathrm{~mol} \% \mathrm{GeO}_{2}$ & 5.063 & 5.188 & 1.025 \\
$15 \mathrm{~mol} \% \mathrm{GeO}_{2}$ & 5.042 & 5.204 & 1.032 \\
\hline
\end{tabular}

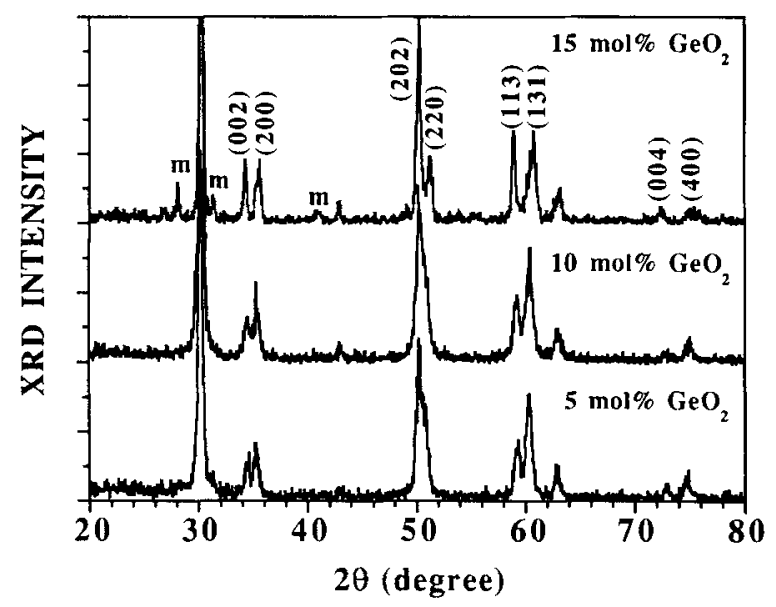

Fig. 1. X-ray diffraction patterns of 5, 10 , and $15 \mathrm{~mol} \% \mathrm{GeO}_{2}-\mathrm{ZrO}_{2}$.

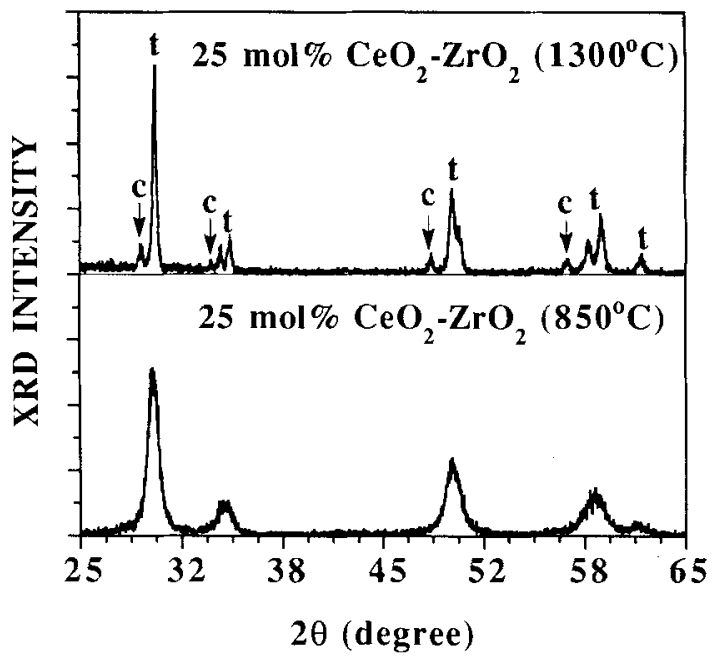

Fig. 2. X-ray diffraction patterns of $25 \mathrm{~mol}_{\%} \mathrm{CeO}_{2}-\mathrm{ZrO}_{2}$ powders calcined at $850^{\circ}$ and $1300^{\circ} \mathrm{C}$.

\section{(2) X-ray Absorption Measurements}

$\mathrm{X}$-ray absorption measurements at the $\mathrm{Zr}-K$ edge, the $\mathrm{Ge}-K$ edge, and the Ce- $L_{m}$ edge were made on Beamline 7-3 at the Stanford Synchrotron Radiation Laboratory (SSRL) under normal operating conditions $(3.0 \mathrm{GeV}, 20$ to $50 \mathrm{~mA})$, using a $\mathrm{Si}(220)$ monochromator. Detuning to $50 \%$ of the incident beam intensity at $\sim 1400 \mathrm{eV}$ above the $\mathrm{Zr}$ - and $\mathrm{Ge}-K$ absorption edges, and $\sim 500 \mathrm{eV}$ above the $\mathrm{Ce}-L_{\mathrm{III}}$ edge, was used. The absorption spectra for pure monoclinic $\mathrm{ZrO}_{2}$, hexagonal $\mathrm{GeO}_{2}$, and fluorite-type $\mathrm{CeO}_{2}$ were measured as reference compounds and for energy calibration. The maximum inflection points of the $\mathrm{ZrO}_{2}, \mathrm{GeO}_{2}$, and $\mathrm{CeO}_{2}$ edges are assigned as 17998,11103 , and $5724 \mathrm{eV}$, respectively. All spectra were measured in transmission mode using ion chambers. The chambers were filled with argon gas for $\mathrm{Zr}-K$ edge and nitrogen gas for $\mathrm{Ge}-K$ and $\mathrm{Ce}-L_{\text {III }}$ edges. Samples were held at $10 \mathrm{~K}$ using an Oxford CF 1204 flow He cryostat. There was no detectable phase change when the samples were cooled from room temperature to $10 \mathrm{~K}$. These procedures are similar to those reported previously. ${ }^{2.3,16}$

The spectra were analyzed using a now well-known procedure. Energy values at $k=0$ were assigned as $18015 \mathrm{eV}$ for the $\mathrm{Zr}-K$ edge, $11120 \mathrm{eV}$ for the Ge- $K$ edge, and $5740 \mathrm{eV}$ for the $\mathrm{Ce}-L_{\mathrm{III}}$ edge. The EXAFS data analysis process was described in the preceding papers. ${ }^{2,3,16}$ In this study, Fourier transforms (FTs) of Zr EXAFS from $k=3$ to $17 \AA^{-1}$ were back-transformed from $R=1.0$ to $2.1 \AA$ to obtain the $\mathrm{Zr}-\mathrm{O}$ shell and $R=$ 2.6 to $3.6 \AA$ for the $\mathrm{Zr}$-cation shell. These FTs give pseudoradial distribution functions around the absorber cations, albeit with their radial distance systematically shifted by a value $\alpha$, which can be determined by data analysis. Curve fitting utilized theoretical amplitude and phase shift functions calculated from the FEFF program. ${ }^{19}$ For Ce and Ge EXAFS, empirical amplitude and phase functions derived from $\mathrm{CeO}_{2}$ and $\mathrm{GeO}_{2}$ were used to fit the $\mathrm{Ce}-\mathrm{O}$ and $\mathrm{Ge}-\mathrm{O}$ shells, with Fourier-filter windows of $1.4-2.1$ and $0.9-1.7 \AA$, respectively.

\section{Results}

\section{(1) EXAFS Spectra at Zr-K Edge}

EXAFS spectra at the $\mathrm{Zr}-K$ edge for $\mathrm{Ce}$ - and Ge-doped zirconia are shown in Fig. 3. All of the samples show the characteristic tetragonal zirconia spectra as previously described., ${ }^{3,16}$ At comparable dopant compositions, the spectra for $\mathrm{Ce}$ - and Ge-doped zirconia are very similar in frequencies and relative amplitudes. The overall amplitude, however, decreases with dopant concentration, which is a common observation for almost all of the solid solutions that we have studied. ${ }^{2.3}$ 
Table II. Crystallographic Data of Reference Compounds

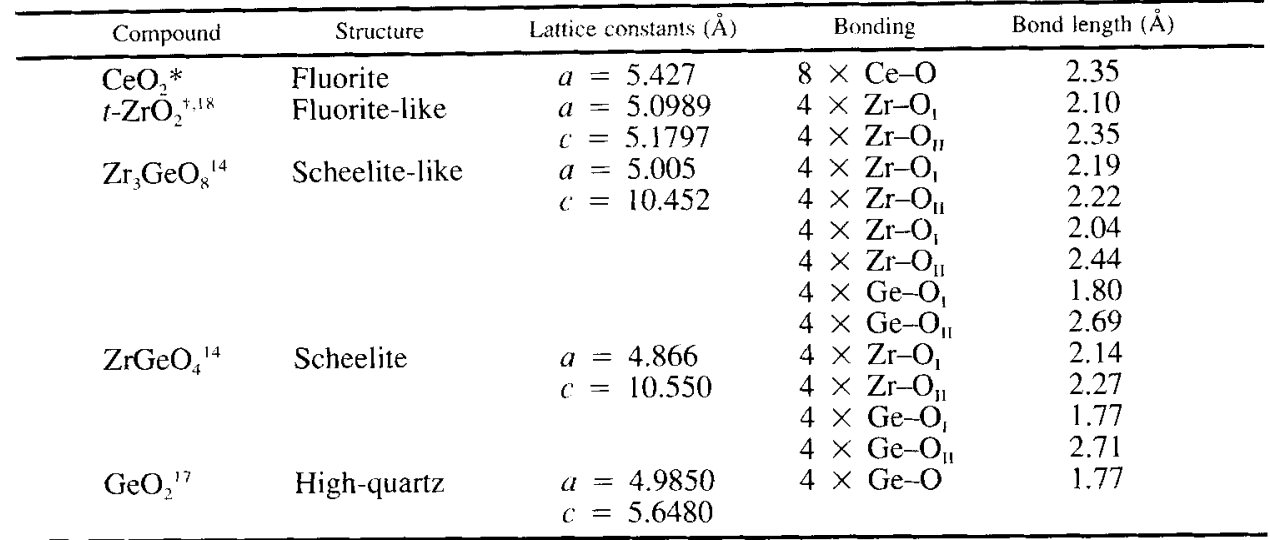

*This study. ${ }^{+}$Containing 3 mol\% $\mathrm{Y}_{2} \mathrm{O}$

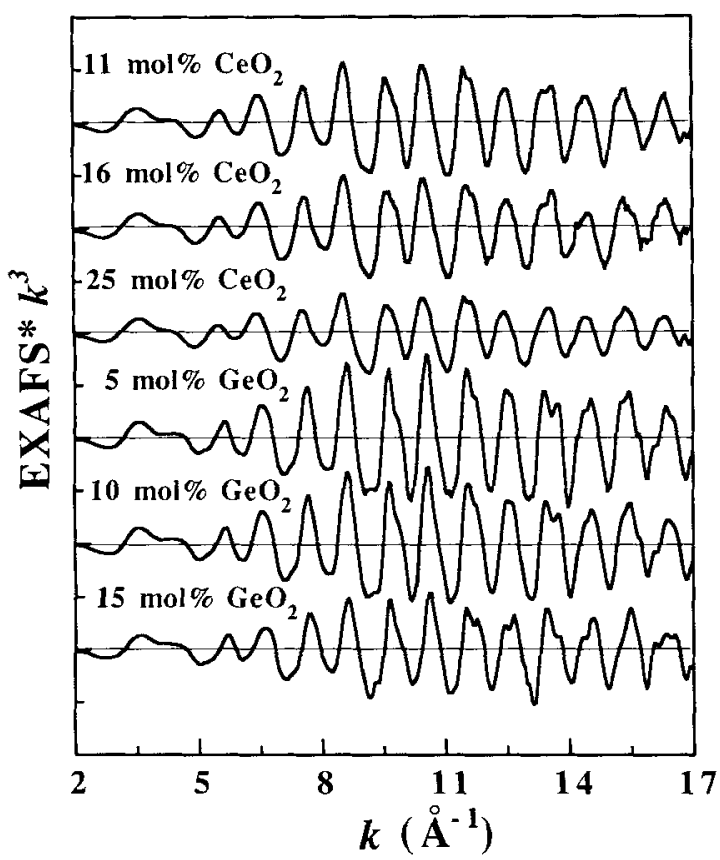

Fig. 3. EXAFS spectra at $\mathrm{Zr}-K$ edge for $\mathrm{Ce}$ - and Ge-stabilized tetragonal zirconia.

Fourier transforms (FTs) of these EXAFS spectra are shown in Figs. $4(a)$ and $(b)$. The first peak corresponds to the $\mathrm{Zr}-\mathrm{O}$ shell and the second to the $\mathrm{Zr}-$ cation shell. A two-subshell structure is observed for the $\mathrm{Zr}-\mathrm{O}$ peak, a feature also found in our previous studies of $\mathrm{Zr}$ spectra in tetragonal zirconia. ${ }^{16}$ This feature is manifested as a shoulder at the high- $R$ side of the first peak and is seen more clearly for Ce-doped samples. The outer $\mathrm{Zr}-\mathrm{O}$ subshell appears to be missing completely for $15 \mathrm{Ge} 10$. The amplitude of the $\mathrm{Zr}$-cation peak decreases with increasing dopant concentration, indicating an increasing structural distortion. Such a trend is again common for almost all of the solid solutions that we studied in the zirconia system and is believed to be the "normal" behavior during alloying. However, the decrease is especially pronounced for $15 \mathrm{Ge} 10$, suggesting a structural discontinuity for this sample. This would be consistent with the formation of an ordered phase $\left(\mathrm{Zr}_{3} \mathrm{GeO}_{8}\right)$ mentioned earlier. The so-called "focusing effect," which enhances the amplitude of the peak at $6.7 \AA$ due to scattering of collinear cations at $1 / 21 / 20$ and 110 positions, ${ }^{20}$ is observed for both systems. This latter feature is also typical of $\mathrm{Zr}$ spectra for tetragonal zirconia. ${ }^{16}$
The bond distance $(R)$, the coordination number $(\mathrm{CN})$, and the bond dispersion $\left(\sigma^{2}\right)$, obtained by curve fitting for the $\mathrm{Zr}-\mathrm{O}$ and $\mathrm{Zr}$-cation shells, are given in Table III. Two sets of bond lengths at 2.09-2.10 and 2.33-2.35 $\AA$ were found for the $\mathrm{Zr}-\mathrm{O}$ shell, regardless of the type of dopant and its concentration. Similarly, the $\mathrm{Zr}$-cation shell has an apparent coordination number of 12 at a distance of 3.61 to $3.63 \AA$ for all samples. These dopant-independent features are consistent with our previous studies ${ }^{16}$ and confirm that the characteristic $\mathrm{Zr}$-centered structure is preserved in the present samples. Table III also gives the fitted values of the Debye-Waller factor, which are attributed primarily to static distortion (at $10 \mathrm{~K}$ ) that increases with increasing dopant concentration. The Ge-doped zirconia samples show increased disorder in their $\mathrm{Zr}-\mathrm{O}$ shells and decreased disorder in their $\mathrm{Zr}$-cation shells compared to Ce-doped zirconia at comparable compositions. The particularly large distortion of the outer subshell of $\mathrm{Zr}-\mathrm{O}$ in $15-\mathrm{mol} \%$ Ge-doped zirconia is due to the mixture of $t-\mathrm{ZrO}_{2}$ and $\mathrm{Zr}_{3} \mathrm{GeO}_{x}$ since the latter has a larger $\mathrm{Zr}-\mathrm{O}$ bond dispersion. (See Table II for the four sets of $\mathrm{Zr}-\mathrm{O}$ distances.) This disorder is probably also responsible for the apparent disappearance of the shoulder on the high- $R$ side of the $\mathrm{Zr}-\mathrm{O}$ peak in $15 \mathrm{Ge} 10$.

\section{(2) EXAFS Spectra at the Ce-L $L_{I I}$ Edge}

Despite the favorable signal/noise ratio, the $\mathrm{Ce}-L_{\mathrm{III}} \mathrm{EXAFS}$ data are only useful to $k \approx 11 \AA^{-1}$ because of the $\mathrm{Ce}-L_{11}$ edge at higher energy. Therefore, the FT of the Ce EXAFS (Fig. 5) suffers from relatively lower resolution, as indicated by the broader peaks. Nevertheless, we can readily compare the behavior of $\mathrm{CeO}_{2}$ (designated as $100 \mathrm{Ce}$ ) and the three $\mathrm{CeO}_{2}-$ $\mathrm{ZrO}_{2}$ solid solutions.

In general, the $\mathrm{Ce}-\mathrm{O}$ and $\mathrm{Ce}$-cation peaks are similar for all of the Ce-doped zirconia solid solutions, although the amplitude decreases with increasing Ce concentration (a "normal" behavior, as discussed above). However, the $\mathrm{Ce}$-cation distance in zirconia is about $0.20 \AA$ shorter than that in $\mathrm{CeO}_{2}$. This difference is significantly larger than would be expected from the change in the phase shift $\alpha$. Because the $\mathrm{Ce}-\mathrm{Ce}$ distance is known to be about $3.83 \AA$ in $\mathrm{CeO}_{2}$, the $\mathrm{Ce}$-cation distance in zirconia can be estimated to be ca. $3.63 \AA$. This is very similar to the $\mathrm{Zr}-$ cation distance of $3.62 \AA$, suggesting that $\mathrm{Ce}^{4+}$ ions substitute randomly for $\mathrm{Zr}^{4+}$ in zirconia. The substitution causes a large distortion of the Ce-centered cation network, as indicated by the very low amplitude of the $\mathrm{Ce}$-cation peak in zirconia solid solutions, especially at higher Ce concentration.

A quantitative analysis of the $\mathrm{Ce}-\mathrm{O}$ shell in Fig. 5 was performed using the amplitude and phase shift functions derived from model compound $\mathrm{CeO}_{2}$. Curve fitting gave the numerical values reported in Table IV. The $\mathrm{Ce}-\mathrm{O}$ bond length in zirconia $(2.30 \AA)$ is shorter than that in ceria $(2.35 \AA)$. This value is consistent with a previous Ce-EXAFS study of tetragonal zirconia. ${ }^{21}$ The $\mathrm{CeO}_{8}$ shell is much more disordered in zirconia 

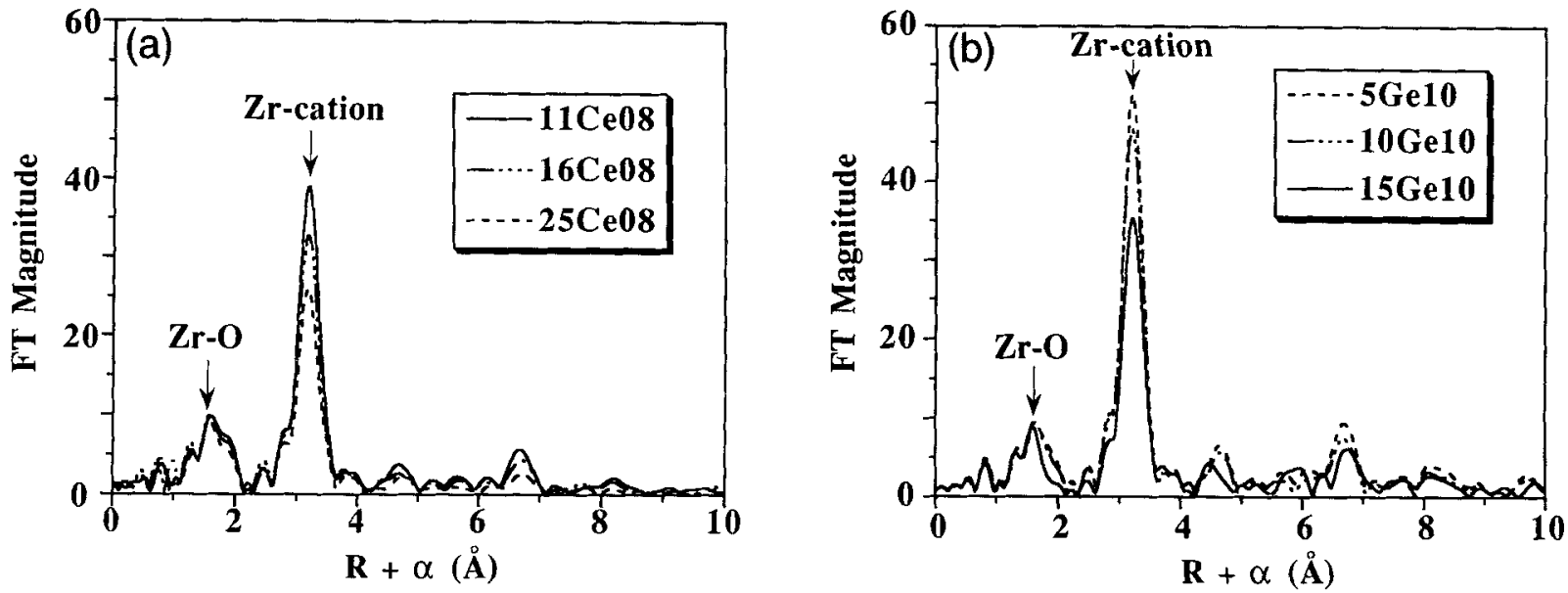

Fig. 4. Fourier transforms of Zr EXAFS for (a) Ce- and (b) Ge-stabilized tetragonal zirconia.

Table III. Fitting Results of Zr EXAFS for Ce- and Ge-Doped Tetragonal Zirconia

\begin{tabular}{|c|c|c|c|c|c|c|}
\hline \multirow[b]{2}{*}{ Composition } & \multicolumn{3}{|c|}{$\mathrm{Zr}$-oxygen } & \multicolumn{3}{|c|}{ Zr-cation } \\
\hline & $R(\AA)$ & $\mathrm{CN}^{*}$ & $\sigma^{2}\left(\AA^{2}\right)$ & $R(\AA)$ & $\mathrm{CN}^{*}$ & $\sigma^{2}\left(\AA^{2}\right)$ \\
\hline $\begin{array}{c}11 \mathrm{~mol}_{(11 \mathrm{Ce} 08)}^{\mathrm{CeO}_{2}} \\
\text { (11 }\end{array}$ & $\begin{array}{l}2.10 \\
2.35\end{array}$ & $\begin{array}{l}4.0 \\
40\end{array}$ & $\begin{array}{l}0.0035 \\
0.0096\end{array}$ & 3.63 & 12.0 & 0.0040 \\
\hline $\begin{array}{c}16 \mathrm{~mol}^{2} \% \mathrm{CeO}_{2} \\
(16 \mathrm{Ce} 08)\end{array}$ & $\begin{array}{l}2.10 \\
2.35\end{array}$ & $\begin{array}{l}4.0 \\
4.0\end{array}$ & $\begin{array}{l}0.0036 \\
0.0106\end{array}$ & 3.63 & 12.0 & 0.0046 \\
\hline $\begin{array}{c}25 \mathrm{~mol}^{2} \% \mathrm{CeO}_{2} \\
(25 \mathrm{Ce} 08)\end{array}$ & $\begin{array}{l}2.10 \\
2.34\end{array}$ & $\begin{array}{l}4.0 \\
4.0\end{array}$ & $\begin{array}{l}0.0040 \\
0.0115\end{array}$ & 3.63 & 12.0 & 0.0056 \\
\hline $5 \underset{(5 \mathrm{Ge} 10)}{\mathrm{mol}_{2}}$ & $\begin{array}{l}2.09 \\
2.35\end{array}$ & $\begin{array}{l}4.0 \\
4.0\end{array}$ & $\begin{array}{l}0.0040 \\
0.0098\end{array}$ & 3.62 & 12.0 & 0.0031 \\
\hline $\begin{array}{c}10 \mathrm{~mol}^{\%} \mathrm{GeO}_{2} \\
(10 \mathrm{Ge} 10)\end{array}$ & $\begin{array}{l}2.09 \\
2.34\end{array}$ & $\begin{array}{l}4.0 \\
4.0\end{array}$ & $\begin{array}{l}0.0041 \\
0.0110\end{array}$ & 3.61 & 12.0 & 0.0035 \\
\hline $\begin{array}{c}15 \mathrm{~mol}^{\%} \mathrm{GeO}_{2} \\
(15 \mathrm{Ge} 10)\end{array}$ & $\begin{array}{l}2.09 \\
2.34\end{array}$ & $\begin{array}{l}4.0 \\
4.0\end{array}$ & $\begin{array}{l}0.0056 \\
0.0174\end{array}$ & 3.61 & 12.0 & 0.0044 \\
\hline
\end{tabular}

*Fit with fixed coordination number.

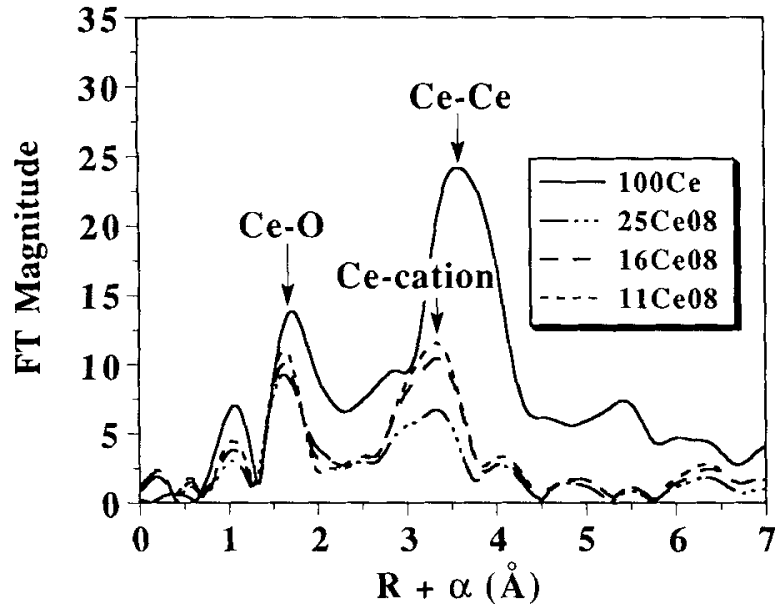

Fig. 5. Fourier transforms of $\mathrm{Ce}-L_{I I I}$ EXAFS for $\mathrm{CeO}_{2}$ and Ce-stabilized tetragonal zirconia.

because of the constraint of the zirconia matrix, which compresses the $\mathrm{Ce}-\mathrm{O}$ distance. With increasing $\mathrm{Ce}$ concentration, the increasing degree of heterogeneity of the matrix solid solution causes additional distortion "normal" for a solid solution.

\section{(3) EXAFS Spectra at the Ge-K Edge}

The EXAFS spectra and the corresponding FTs at the Ge- $K$ edge for Ge-stabilized tetragonal zirconia and pure hexagonal $\mathrm{GeO}_{2}$ are shown in Figs. 6 and 7. All three spectra for tetragonal zirconia are similar, but different from those for $\mathrm{GeO}_{2}$. This demonstrates that $\mathrm{Ge}^{4+}$ has different local structures in zirconia and in $\mathrm{GeO}_{2}$. Comparing the Ge-FTs and Zr-FTs (Fig. 4(b)) for the zirconia solid solutions, we also note a close similarity in the positions of cation-cation peaks, indicating Ge substitution for $\mathrm{Zr}$. Surprisingly, unlike the case for $\mathrm{Ce}^{4-}$ or for trivalent dopants $\left(\mathrm{Ge}^{3+}, \mathrm{Y}^{3+}, \mathrm{Fe}^{3+}\right.$, and $\left.\mathrm{Ga}^{3+}\right)$, the amplitude of $\mathrm{Ge}$ EXAFS increases with increasing Ge concentration. This trend is most easily seen in the FTs. The increased EXAFS amplitude is seen for all of the Ge-cation peaks, out to $R>10 \AA$, and is particularly large for $15 \% \mathrm{GeO}_{2}$. Note also that the amplitude of the $\mathrm{Zr}$ EXAFS (and FTs) for the same $\mathrm{GeO}_{2}-\mathrm{ZrO}_{2}$ samples decreases with increasing Ge concentration. Thus, the "abnormal" amplitude variation is restricted to the Ge-centered local environment.

The abrupt increase in peak height for $15 \mathrm{~mol} \% \mathrm{GeO}_{2}-\mathrm{ZrO}_{2}$ can be attributed to formation of $\mathrm{Zr}_{3} \mathrm{GeO}_{8}$. This phase gives rise to some unusually high amplitudes, including ones for several high-order peaks. Similar high-order enhancement has not been observed for other $\mathrm{ZrO}_{2}$-containing systems that we have studied. Many of the features attributable to this second phase are already present for solid solutions containing less $\mathrm{GeO}_{2}$, suggesting the incipient formation of a $\mathrm{Zr}_{3} \mathrm{GeO}_{8}$ phase even at 5 $\mathrm{mol} \% \mathrm{GeO}_{2}$.

Utilizing amplitude and phase shift functions obtained from the $\mathrm{Ge}-\mathrm{O}$ shell in hexagonal $\mathrm{GeO}_{2},{ }^{17}$ we obtained the fitting results given in Table IV. A Ge-O bond distance of 1.80 to 1.81 $\AA$ with 4-fold coordination is obtained for all three doped samples. This is slightly longer than the $\mathrm{Ge}-\mathrm{O}$ distance in $\mathrm{GeO}_{2}$ but is in excellent agreement with the previous neutron-diffraction study for the $\mathrm{Ge}-\mathrm{O}$ bonding $(1.80 \AA \times 4)$ in $\mathrm{Zr}_{3} \mathrm{GeO}_{8}{ }^{14}$ (see Table II). Thus, the Ge-O arrangement in tetragonal zirconia solid solution is similar to that in the ordered phase $\mathrm{Zr}_{3} \mathrm{GeO}_{3}$. 
Table IV. EXAFS Results of Ce-O and Ge-O Bonding in Zirconia*

\begin{tabular}{ccccc}
\hline Composition & Bonding & $R(\AA)$ & $\mathrm{CN}^{+}$ & $\Delta \sigma^{2}\left(\AA^{2}\right)$ \\
\hline Pure $\mathrm{CeO}_{2}(100 \mathrm{Ce})$ & $\mathrm{Ce}-\mathrm{O}$ & 2.35 & 8.0 & 0.0000 \\
$11 \mathrm{~mol}^{2} \mathrm{CeO}_{2}(1 \mathrm{Ce} 08)$ & $\mathrm{Ce}-\mathrm{O}$ & 2.30 & 8.0 & 0.0061 \\
$16 \mathrm{~mol}_{2} \mathrm{CeO}_{2}(16 \mathrm{Ce} 08)$ & $\mathrm{Ce}-\mathrm{O}$ & 2.30 & 8.0 & 0.0064 \\
$25 \mathrm{~mol}_{0} \mathrm{CeO}_{2}(25 \mathrm{Ce} 08)$ & $\mathrm{Ce}-\mathrm{O}$ & 2.30 & 8.0 & 0.0065 \\
Pure GeO$(100 \mathrm{Ge})$ & $\mathrm{Ge}-\mathrm{O}$ & 1.77 & 4.0 & 0.0000 \\
$5 \mathrm{~mol} \% \mathrm{GeO}_{2}(5 \mathrm{Ge} 10)$ & $\mathrm{Ge}-\mathrm{O}$ & 1.81 & 4.0 & 0.0001 \\
$10 \mathrm{~mol}_{2} \mathrm{GeO}_{2}(10 \mathrm{Ge} 10)$ & $\mathrm{Ge}-\mathrm{O}$ & 1.81 & 4.0 & 0.0001 \\
$15 \mathrm{~mol}_{\%} \mathrm{GeO}_{2}(15 \mathrm{Ge} 10)$ & $\mathrm{Ge}-\mathrm{O}$ & 1.80 & 4.0 & 0.0001 \\
\hline
\end{tabular}

${ }^{*} \mathrm{Ce}-\mathrm{O}$ and $\mathrm{Ge}-\mathrm{O}$ bonding in the parent oxides used as fitting models. 'Fit with fixed coordination number.

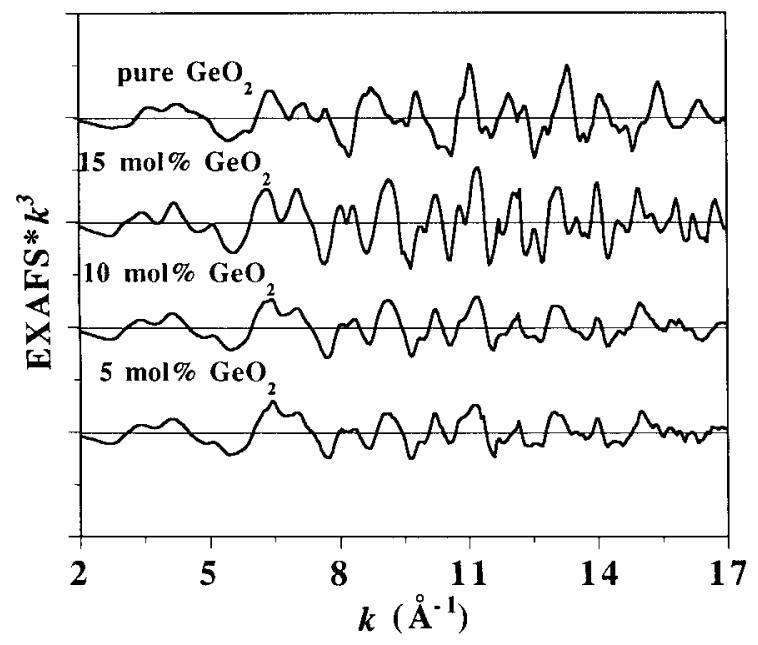

Fig. 6. EXAFS spectra at $\mathrm{Ge}-\mathrm{K}$ edge for $\mathrm{GeO}_{2}$ and Ge-stabilized tetragonal zirconia.

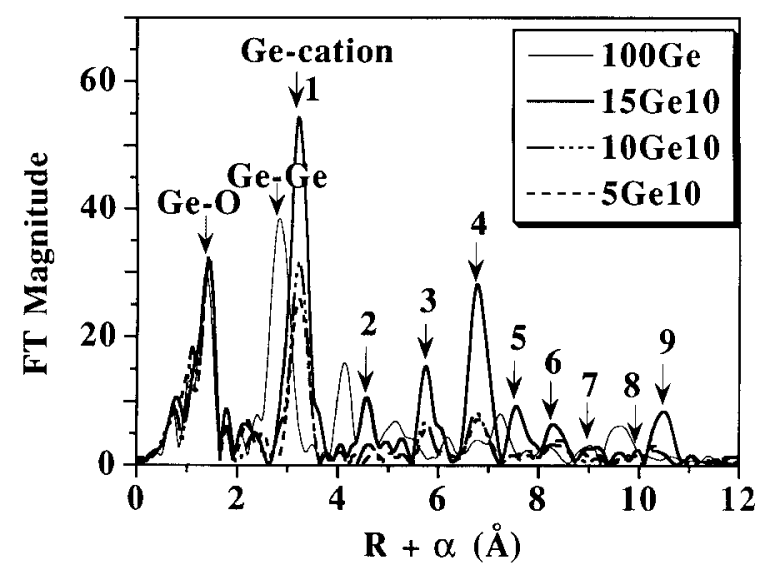

Fig. 7. Fourier transforms of Ge EXAFS for $\mathrm{GeO}_{2}$ and $\mathrm{Ge}$-stabilized tetragonal zirconia.

Remarkably, the Debye-Waller factors for the Ge-O shell are quite small. Since the reference compound, hexagonal $\mathrm{GeO}_{2}$, has nearly ideal $\mathrm{GeO}_{4}$ tetrahedra, these small $\Delta \boldsymbol{\sigma}^{2}$ values imply that there is negligible distortion of the $\mathrm{Ge}-\mathrm{O}$ tetrahedron, other than a slight dilatation, in either tetragonal zirconia or in $\mathrm{Zr}_{3} \mathrm{GeO}_{8}$. This gives rise to a very sharp first peak in all four spectra in Fig. 7. This peak is more than 3 times higher than either the $\mathrm{Zr}-\mathrm{O}$ or the $\mathrm{Ce}-\mathrm{O}$ peaks of Figs. 3 and 4.

The second FT peak corresponds to the next-nearest neighbors (NNN) around a central $\mathrm{Ge}^{4+}$, i.e., the first $\mathrm{Ge}$-cation $\left(\mathrm{Zr}^{4+}\right.$ and/or $\left.\mathrm{Ge}^{4+}\right)$ shell. The higher-order peaks $(>3 \AA)$ are outer $\mathrm{Ge}-$ cation shells since outer $\mathrm{Ge}-\mathrm{O}$ shells are less readily observable because of the weak scattering function of oxygen. Quantitative fitting of the first Ge-cation ( $\mathrm{Zr}$ and/or $\mathrm{Ge}$ ) shell was performed using calculated (FEFF) amplitude and phase functions of a $\mathrm{Ge}-\mathrm{Zr}$ pair with a distance of $3.62 \AA$. Since the phase shift functions of $\mathrm{Zr}$ and $\mathrm{Ge}$ have similar $k$ dependence, ${ }^{20}$ the bond distance can be determined with reasonable accuracy without considering the $\mathrm{Ge}-\mathrm{Ge}$ scattering contribution. The coordination number and Debye-Waller factor, however, are subject to greater uncertainty due to the very different amplitude functions between $\mathrm{Ge}$ and $\mathrm{Zr}$; thus, the latter fitting results are not discussed. In all cases, a distance of 3.59 to $3.60 \AA$ is obtained, which is similar to that of the corresponding $\mathrm{Zr}-$ cation shell $(3.61$ to $3.62 \AA$, see Table III). This indicates that the $\mathrm{Ge}^{4+}$ ions substitute for $\mathrm{Zr}^{4+}$ in the $\mathrm{Zr}$ network.

Based on the curve-fitting distance and the Ge-cation peak position (Fig. 7), the apparent phase shift correction is ca. $0.5 \AA$. Using this phase shift, the expected peak positions $(R+\alpha)$ for an ideal fcc cation sublattice can be calculated. The pertinent absorber-scatter pairs are shown schematically in Fig. 8 for $\mathrm{Zr}_{3} \mathrm{GeO}_{8}$ using an fcc reference lattice. The calculated distances are indicated by the arrows in Fig. 7. For 15Ge10, for which the $\mathrm{Ge}$ spectrum primarily reflects the Ge-centered $\mathrm{Zr}_{3} \mathrm{GeO}_{8}$ domains, all of the high-order peaks coincide with the calculated cation-cation pair distances (lattice parameter $=5.2 \AA$ ). This provides a direct confirmation that the Ge-cation network of $\mathrm{Zr}_{3} \mathrm{GeO}_{8}$ is nearly face-centered cubic and fluorite-like. Indeed, of the Ge-cation peaks expected for an ideal fcc arrangement, only peak 8 is too weak to be detected above the noise. Peaks 5, 7, and 9 are seen for the first time in our study. The amplitude enhancement for peaks 4 and 9 is due to the so-called "focusing effect." These peaks are attributed to face diagonal Ge-cation pairs which have a linear absorber-scatterscatter geometry with at least one intervening scatterer. Because of this stringent requirement, the fact that peaks 4 and 9 are intense provides additional evidence that the Ge-cation network in $\mathrm{Zr}_{3} \mathrm{GeO}_{8}$ is face-centered cubic with only little distortion.

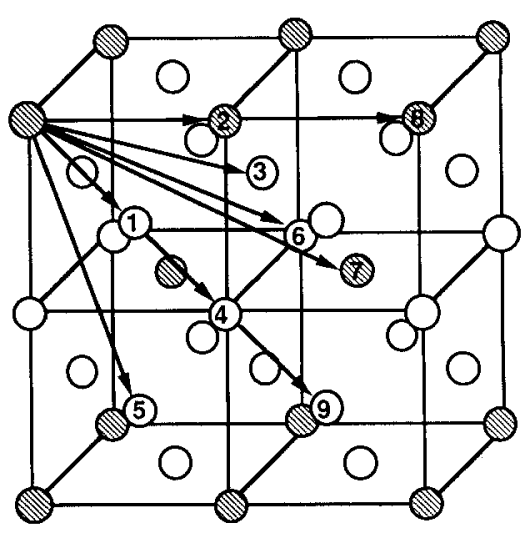

$\mathrm{Zr}$ Ge

Fig. 8. Cation sublattice in $\mathrm{Zr}_{3} \mathrm{GeO}_{8}$. 
The amplitudes of the Ge-cation shells increase with increasing Ge content. This "abnormal" observation can be explained by increasing ordering of the Ge-centered cation network. In contrast, the $\mathrm{Zr}$-centered cation network is probably still disordered, and hence distorted, in the matrix outside these ordered domains, thus accounting for the lower Zr EXAFS amplitude described above. This picture seems reasonable in view of the Ge concentrations, which are less than required $(25 \mathrm{~mol} \%)$ to form $\mathrm{Zr}_{3} \mathrm{GeO}_{8}$ completely. Finally, while peak 1 increases continuously from 5 to $15 \mathrm{~mol}_{\%} \mathrm{GeO}_{2}$, the outer peaks, corresponding to Ge-cation pairs extending beyond the first cubic cell, are only seen for $15 \mathrm{Ge} 10$. This suggests that although the dissolved $\mathrm{Ge}^{4+}$ ions cause local ordering similar to that of $\mathrm{Zr}_{3} \mathrm{GeO}_{8}$, these domains extend only to a spatial distance on the order of one cubic cell from the center Ge at low Ge concentrations. It is remarkable that ordering on this scale, which is unlikely to be detectable by other techniques, can be revealed by EXAFS.

\section{(4) XANES Spectra}

$\mathrm{X}$-ray absorption near edge spectra of the present series of samples can be found in the doctoral thesis of the principal author ${ }^{22}$ and are not shown here. At the $\mathrm{Zr}-K$ edge they show the characteristic XANES features for tetragonal zirconia. ${ }^{16}$ At the Ce- $L_{11}$ edge, the spectra for the doped samples are similar to that of pure $\mathrm{CeO}_{2}{ }^{23,24}$ The very similar XANES spectra for $\mathrm{Ce}$ in $\mathrm{CeO}_{2}$ and $\mathrm{Ce}$-doped zirconia solid solutions indicate that the same valence state prevails in all of the samples.

The XANES spectra at the Ge- $K$ edge in tetragonal zirconia are all similar but very different from that for $\mathrm{GeO}_{2}$, reflecting different atomic structures.

\section{Discussion}

\section{(1) Local Structures of Zirconia with Tetravalent Dopants}

As in other solid solutions, $\mathrm{ZrO}_{2}-\mathrm{CeO}_{2}$ and $\mathrm{ZrO}_{2}-\mathrm{GeO}_{2}$ have very different host and dopant cation- $\mathrm{O}$ distances but very similar host and dopant cation-cation distances. ${ }^{3}$ In most respects, the local environments of both the host and dopant cations are characteristic of the tetragonal polymorph and independent of the dopant. In contrast, the dopant-O environments are somewhat similar to those of the corresponding parent oxides but with altered bond distance. Thus, for the oversized $\mathrm{Ce}^{4+}$, the $\mathrm{CeO}_{8}$ cube is compressed in zirconia as compared to that in $\mathrm{CeO}_{2}$, while for undersized $\mathrm{Ge}^{4+}$, the $\mathrm{GeO}_{4}$ tetrahedron is dilated in zirconia as compared to that in $\mathrm{GeO}_{2}$. Such a straightforward comparison was not possible in our previous study of trivalent cations because a change of coordination number for trivalent cations between parent oxides and doped zirconia was often encountered, making direct comparison inappropriate. However, an analogous compression of oversized $\mathrm{YO}_{8}$ and $\mathrm{GdO}_{8}$ was noted in doped zirconia ${ }^{3}$ when compared with the more relaxed configurations tabulated in Shannon's table. ${ }^{25}$ The compression for $\mathrm{Ce}^{4+}$ is smaller than that for $\mathrm{Y}^{3+}$ and $\mathrm{Gd}^{3+}$ (see Ref. 3) because of the smaller misfit for $\mathrm{CeO}_{8}$. (The ionic radii for 8 -fold coordination are as follows: $\mathrm{Ce}^{4+}, 0.97 \AA \mathrm{A}^{3+} \mathrm{Y}^{3+}$, $1.019 \AA ; \mathrm{Gd}^{3+}, 1.053 \AA$; and $\mathrm{Zr}^{4+}, 0.84 \AA$. $^{24}$ )

The substitution of undersized $\mathrm{Ge}^{4+}$ for $\mathrm{Zr}^{4+}$ leads to an ordered arrangement in the cation network which eventually gives rise to an ordered $\mathrm{Zr}_{3} \mathrm{GeO}_{8}$ phase at high $\mathrm{Ge}^{4+}$ concentration $(25 \mathrm{~mol} \%)$, but the same local oxygen environment of $\mathrm{Ge}^{4+}$ prevails even at lower concentration. The scheelite-like structure of $\mathrm{Zr}_{3} \mathrm{GeO}_{8}$ (Table II) has two sets of Ge-O distances, 1.80 and $2.69 \AA$, both with tetrahedral coordination. ${ }^{14}$ Only the inner oxygen tetrahedron $\left(\mathrm{Ge}-\mathrm{O}_{\mathrm{I}}\right)$ contributes to the observed first FT peak (Fig. 7) at the same bond distance. The outer $\mathrm{Ge}-\mathrm{O}_{\text {II }}$ peak is too weak to be detected.

Cation networks in all of the tetragonal zirconia solid solutions investigated thus far are essentially fcc type. Ce doping leads to some disorder whereas Ge doping remarkably enhances order. The latter is highly unusual. In particular, the resolution of the very strong high-order peaks in FTs, especially the one at $R+\alpha \approx 10.5 \AA$, is remarkable for the EXAFS. In the following, we will utilize this local structure information to address the issues on tetragonality and phase stability.

\section{(2) Tetragonality}

Tetragonal zirconia may be viewed as a layer structure. ${ }^{26}$ In this picture, tetragonality is attributed to the strong bonding of $\mathrm{Zr}-\mathrm{O}_{\mathrm{I}}(2.10 \AA)$ within the layers and weak bonding of $\mathrm{Zr}-\mathrm{O}_{\mathrm{II}}$ $(2.34 \AA)$ between the layers. Both $\mathrm{O}_{1}$ and $\mathrm{O}_{\mathrm{II}}$ form a tetrahedron, though of a different size, around $\mathrm{Zr}$. The introduction of $\mathrm{Ce}^{4+}$ ions, which adopt a more symmetric 8-fold coordination because of their larger size, has the effect of assimilating these two types of bonding and destroying the layer structure. This is shown schematically in Fig. 9 and accounts for the decrease in the $c / a$ ratio with Ce doping. The decrease, in reality, is relatively small, so that tetragonality of dilute solutions does not extrapolate to zero at $100 \% \mathrm{CeO}_{2}{ }^{6}$

Oversized trivalent cations, which also prefer 8-fold coordination, ${ }^{2,3}$ are known to cause reduction in tetragonality much more effectively than $\mathrm{Ce}^{4+}$. The tetragonality decrease in this case is aided by the creation of oxygen vacancies. This mechanism may be intuitively understood as being due to the relief of oxygen "overcrowding" between the layers and especially around $\mathrm{Zr}^{4+}$. Since only the concentration of the vacancy matters, the exact magnitude of oversize is less consequential. Thus, the tetragonality vanishes at $18 \mathrm{~mol}^{2} \mathrm{MO}_{1.5}$ regardless of ionic sizes. ${ }^{9.27}$ These dopants need to be oversized, though, because only oversized trivalent dopants leave all of the oxygen vacancies to $\mathrm{Zr}^{4+}$ and thereby exert the greatest effect on tetragonality reduction. Undersized trivalent dopants tend to be associated with oxygen vacancies themselves so that their ability to relieve the oxygen crowding around $\mathrm{Zr}^{4+}$ is diminished. ${ }^{3,27}$ In short, the dopant effect on tetragonality reduction decreases in the order of oversized trivalent cation, undersized trivalent cation, and oversized tetravalent cation.

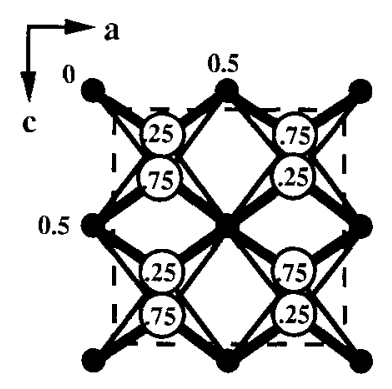

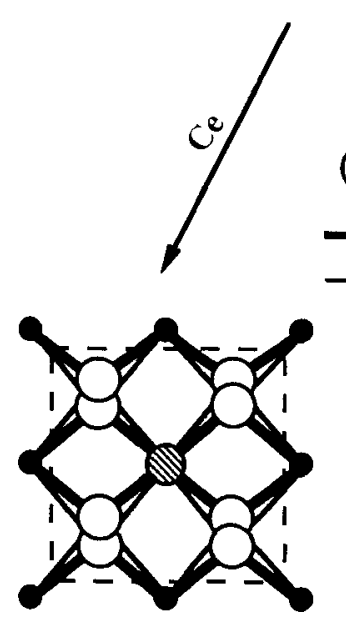

c/a decreases
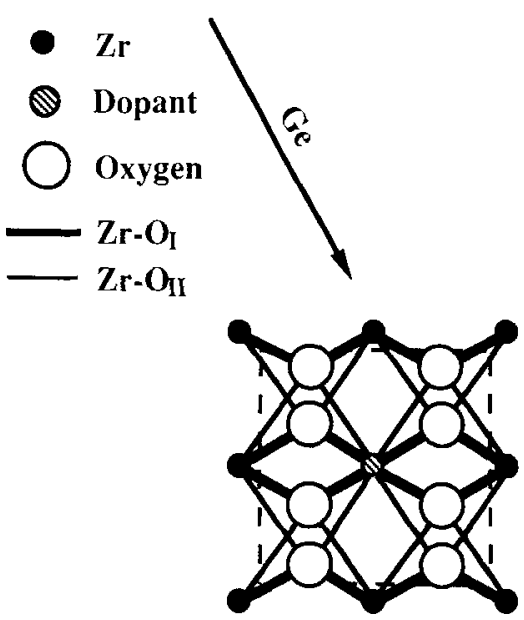

c/a increases
Fig. 9. Schematic illustration for variation of tetragonality of zirconia solid solutions. (Numbers indicate atom positions in $b$ direction.) 
The tetragonality of the zirconia solid solution increases with increasing concentration of the undersized Ge dopant. This can also be rationalized by the layer structure of tetragonal zirconia. As described above, the Ge-O coordination in both zirconia solid solutions and $\mathrm{Zr}_{3} \mathrm{GeO}_{8}$ is bifurcated into two subshells, $\mathrm{Ge}-\mathrm{O}_{1}$ and $\mathrm{Ge}-\mathrm{O}_{1 \mathrm{I}}$. This is analogous to the splitting of the $\mathrm{Zr}-\mathrm{O}$ shell. The $\mathrm{M}-\mathrm{O}$ bond strength, as judged by bond distances, decreases in the following order, $\mathrm{Ge}-\mathrm{O}_{\mathrm{I}}>\mathrm{Zr}-\mathrm{O}_{1}>$ $\mathrm{Zr}-\mathrm{O}_{11}>\mathrm{Ge}-\mathrm{O}_{11}$; i.e., the bond strength disparity between $\mathrm{ZrO}_{1}$ and $\mathrm{ZrO}_{11}$ should be increased if $\mathrm{Zr}$ is substituted by Ge. Therefore, Ge doping causes the bonding within the layers to be strengthened while that between the layers weakened, thus increasing the tetragonality. When the ordered $\mathrm{Zr}_{3} \mathrm{GeO}_{8}$ and $\mathrm{ZrGeO}_{4}$ structures finally form, there is an additional small increase in the tetragonality beyond the reference trend line of the solid solution. ${ }^{9}$ This is probably due to a collective relaxation effect and is again most likely related to the different bond strengths of $\mathrm{Ge}-\mathrm{O}_{1}$ and $\mathrm{Ge}-\mathrm{O}_{\mathrm{II}}$ bonds. This mechanism is schematically depicted in Fig. 9 and is believed applicable for all undersized tetravalent solutes.

\section{(3) Phase Stability}

The varying tetragonal stability in different zirconia solid solutions is now rationalized. First, we recognize that the instability of tetragonal zirconia is rooted in the small size of $\mathrm{Zr}^{4+}$, which is unfavorable for 8-fold oxygen coordination normally required for the fluorite structure.' Thus, the cation network is strained and oxygen overcrowding is present in tetragonal zirconia. We have previously found structural evidence of this instability in the temperature dependence of EXAFS ${ }^{28}$ which has a more severe thermal distortion in tetragonal zirconia than in all other (thermodynamically more stable) polymorphs (monoclinic, cubic, and orthorhombic). In addition, we found that at $10 \mathrm{~K}$, when thermal distortion is largely frozen and the $\mathrm{NNN} \mathrm{Zr}-\mathrm{Zr}$ peak in the FT is strongest in tetragonal phase, the amplitude of higher-order peaks diminishes more rapidly for the tetragonal phase than for other phases, indicating a much stronger contribution of incoherent scattering at higher orders in the former. ${ }^{16}$ Therefore, stabilization of tetragonal phase must be achieved via a relief of its internal strain.

Inasmuch as oversized tetravalent dopants (such as $\mathrm{Ce}^{4+}$ ) dilate the cation network and $\mathrm{Zr}$-associated oxygen vacancies (from trivalent cations) relieve oxygen overcrowding, both are expected to cause increased tetragonal stability because of the decrease in strain energy. In these cases, the tetragonality appears to be a good indicator of the instability of the cation network; i.e., lower tetragonality is accompanied by an increase in the stability of the network against monoclinic distortion. Stabilization of the tetragonal structure by undersized $\mathrm{Ge}^{4+}$ is obviously different. In this case, the tetragonality increases at the same time that the stability is enhanced. The stabilizing effect is apparently achieved by cation ordering. The evidence for the reduced internal strain energy lies in the increased amplitude of the Ge-cation peak even at very large distances, indicating very little distortion over at least a distance of $11 \AA$ from a central $\mathrm{Ge}$ atom. The overcrowding in this case is apparently relieved by the full development of bifurcated tetrahedral bondings for both $\mathrm{Zr}-\mathrm{O}$ and $\mathrm{Ge}-\mathrm{O}$ in the layer-like structure. In so doing, the tetragonal structure gains thermodynamic stability while the tetragonality increases simultaneously. Indeed, tetragonality is an indicator of stability in this case. For example, the highly tetragonal terminal phase, $\mathrm{Zr}_{3} \mathrm{GeO}_{8}$, is highly stable.

For completeness, we turn finally to the cubic phase in order to rationalize its stabilization. We have shown previously ${ }^{2,3}$ that the availability of free oxygen vacancies is central to forming the cubic zirconia structure with 7 -fold $\mathrm{Zr}-\mathrm{O}$ polyhedron as the elementary structural unit. At the cubic boundary, the ratio of $\mathrm{ZrO}_{7} / \mathrm{ZrO}_{8}$ is approximately 1 ; i.e., the population of $\mathrm{ZrO}_{7}$ gains majority in the cubic phase. Thus, it is not surprising that no cubic zirconia solid solution has been reported for the $\mathrm{ZrO}_{2}-$ $\mathrm{GeO}_{2}$ or $\mathrm{ZrO}_{2}-\mathrm{TiO}_{2}$ systems, since there are no vacancies in these systems. Nevertheless, in the $\mathrm{ZrO}_{2}-\mathrm{CeO}_{2}$ system, a cubic phase should form because $\mathrm{CeO}_{2}$ itself is a cubic fluorite structure. The phase diagram ${ }^{5}$ of the $\mathrm{ZrO}_{2}-\mathrm{CeO}_{2}$ system shows a cubic-tetragonal two-phase regime between 18 and $70 \mathrm{~mol} \%$ $\mathrm{CeO}_{2}$ at intermediate temperatures. This can be rationalized if we postulate that the cubic structure could form once the percolation limit for $\mathrm{Ce}$ in the fcc lattice $(19.8 \%)^{29}$ is exceeded. Under this condition, a locally "cubic" environment surrounding Ce will link up to form cubic domains that phase-separate the solid solution into tetragonal and cubic regions. (This is an extension of the previous picture in which the $\mathrm{ZrO}_{7}$ network is connected.) This two-phase regime will continue until the $\mathrm{Zr}$ ions become the minority species and fully surrounded by the cubic matrix. This appears to occur at $70 \% \mathrm{CeO}_{2}$ judged by the steep decrease of $c / a$ near this composition, reducing $c / a$ to unity. ${ }^{30}$ At higher temperatures $\left(>1900^{\circ} \mathrm{C}\right)$ a genuine cubic $\mathrm{Zr}(\mathrm{Ce}) \mathrm{O}_{2}$ solid solution, partially stabilized by oxygen vacancies, can exist at higher $\mathrm{Zr}$ concentrations ${ }^{5.31}$ In view of the similarity of the phase diagrams, the above picture could apply to the $\mathrm{ZrO}_{2}-\mathrm{UO}_{2}$ system and all other oversized tetravalent dopants.

\section{Conclusions}

$\mathrm{Zr}$ in both $\mathrm{Ce}$ - and Ge-doped tetragonal zirconia has a characteristic local structure, as previously described in our studies, ${ }^{2.3}$ with two sets of tetrahedrally coordinated $\mathrm{Zr}-\mathrm{O}$ polyhedra $(2.10 \AA \times 4$ and $2.33 \AA \times 4)$ and a 12 -fold coordinated $\mathrm{Zr}-$ cation shell at $3.62 \AA$. Further conclusions arrived at in this study are the following:

(1) Both the oversized $\left(\mathrm{Ce}^{4+}\right)$ and undersized $\left(\mathrm{Ge}^{4+}\right)$ tetravalent dopants have significantly different oxygen coordination from that of the host cation. The Ce forms a random substitutional solid solution with $\mathrm{Zr}$, while the Ge dissolves in the cation sublattice but is arranged in ordered domains. In both cases, the cation-cation distance is not altered by alloying.

(2) Oversized $\mathrm{CeO}_{8}$ polyhedra are observed in tetragonal zirconia with a $\mathrm{Ce}-\mathrm{O}$ bond length of $2.30 \AA$. This distance is longer than the mean $\mathrm{Zr}-\mathrm{O}$ distance of the host but shorter than the $\mathrm{Ce}-\mathrm{O}$ distance in pure $\mathrm{CeO}_{2}$. The 8 -fold oxygen coordination around the oversized $\mathrm{Ce}^{4+}$ ions and the dilation it causes decrease tetragonality of zirconia and stabilize its tetragonal structure by the relief of oxygen overcrowding.

(3) The undersized Ge in zirconia solid solutions is tetrahedrally coordinated with $\mathrm{O}$ with a $\mathrm{Ge}-\mathrm{O}$ distance of $1.81 \AA$. This distance is shorter and its bond is presumably stronger than the $\mathrm{Zr}-\mathrm{O}_{\mathrm{I}}$ bond, thus it enhances the anisotropy of the tetragonal layer structure. The local $\mathrm{Ge}-\mathrm{Zr}$ ordering is reminiscent of a scheelite-like $\mathrm{Zr}_{3} \mathrm{GeO}_{8}$ structure which apparently relieves the internal strain energy of the $\mathrm{Zr}$ cation sublattice. Thus, despite the increase in tetragonality, the tetragonal solid solution can be stabilized effectively by Ge doping.

(4) Undersized tetravalent dopants do not form a cubic zirconia solid solution. Oversized tetravalent dopants decrease the tetragonality very slowly at dilute concentrations. However, a cubic solid solution eventually forms when the cubic-like surrounding of the oversized tetravalent dopant becomes the majority matrix at around $70 \%$.

\section{References}

'S. M. Ho, "On the Structural Chemistry of Zirconium Oxide," Mater. Sci. Eng., 54, 23-29 (1982).

${ }^{2} \mathrm{P}$. Li, I-W. Chen, and J. E. Penner-Hahn, "X-ray Absorption Studies of Zirconia Polymorphs II. Effect of $\mathrm{Y}_{2} \mathrm{O}_{3}$ Dopant on Zirconia Structure," Phys. Rev. B, 48 [14] 10074-81 (1993).

${ }^{3} \mathrm{P}$. Li, I-W. Chen, and J. E. Penner-Hahn, "Effect of Dopants on Zirconia Stabilization-An X-ray Absorption Study: I, Trivalent Dopants," I. Am. Ceram. Soc., 77 [1] 118-28 (1994)

${ }^{4}$ R. J. Stöcker, "Contribution a l'Étude des Properiétés des Solutions Solides Réfractaires, A Base de Zircone et de la Zircone Cubique," Ann. Chim., 6, 1459 $502(1960)$

${ }^{5}$ E. Tani, M. Yoshimura, and S. Somiya, "Revised Phase Diagram of the $\mathrm{ZrO}_{2}-\mathrm{CeO}_{2}$ Below $1400^{\circ} \mathrm{C}, " J$. Am. Ceram. Soc., 66 [7] 506-509 (1983).

${ }^{6} \mathrm{~K}$. Tsukuma and M. Shimada, "Strength, Fracture Toughness and Vickers Hardness of $\mathrm{CeO}_{2}$-Stabilized Tetragonal $\mathrm{ZrO}_{2}$ Polycrystals (Ce-TZP)," J. Mater Sci., 20, 1178-84 (1985). 
${ }^{7} \mathrm{C}$. L. Lin, D. Gan, and P. Shen, "The Effect of $\mathrm{TiO}_{2}$ Addition on the Microstructure and Transformation of $\mathrm{ZrO}_{2}$ with 3 and 6 mol\% $\mathrm{Y}_{2} \mathrm{O}_{3}, "$ Mater. Sci. Eng., A129, 147-55 (1990).

${ }^{8}$ V. C. Pandolfelli, J. A. Rodrigues, and R. Stevens, "Effects of $\mathrm{TiO}_{2}$ Addition on the Sintering of $\mathrm{ZrO}_{2} \cdot \mathrm{TiO}_{2}$ Compositions and on the Retention of the Tetragonal Phase of Zirconia at Room Temperature," J. Mater. Sci., 26, 5327-34 (1991)

'J. Lefèvre, "Fluorite-Type Structural Phase Modifications in Systems Having a Zirconium or Hafnium Oxide Base," Ann. Chim., 8, 117-49 (1963).

"V. C. Pandolfelli, W. M. Rainforth, and R. Stevens, "Tetragonal Zirconia Polycrystais in the $\mathrm{ZrO}_{2}-\mathrm{TiO}_{2}-\mathrm{CeO}_{2}$ System"; pp. 161-65 in Proceedings of the 1 st European Ceramic Society Conference, Vol. 2. Edited by G. Dewith, R. A Terpstra, and R. Metseloar. Elsevier Science Publishing, New York, 1989.

"V. S. Stubican, "Phase Equilibria and Metastabilities in the Systems $\mathrm{ZrO}_{2}$ $\mathrm{MgO}, \mathrm{ZrO}_{2}-\mathrm{CaO}$, and $\mathrm{ZrO}_{2}-\mathrm{Y}_{2} \mathrm{O}_{3}{ }^{\prime} ;$ pp. $7 \mathrm{I}-82$ in Advances in Ceramics, Vol 24. Edited by S. Somiya, N. Yamamoto, and H. Hanagida. American Ceramic Society, Westerville, $\mathrm{OH}, 1988$.

12I. Cohen and B. E. Schaner, "A Metallographic and X-ray Study of the $\mathrm{UO}_{2}-$ $\mathrm{ZrO}_{2}$ System," J. Nucl. Mater., 9 [1] 18-52 (1963)

${ }^{13}$ P. Duwez and E. Loh, "Phase Relationships in the System Zirconia-Thoria," J. Am. Ceram. Soc., 40 [9] 321-24 (1957).

${ }^{14}$ A. Ennaciri, D. Michel, M. Perez y Jorba, and J. Pannetier, "Neutron Diffraction Determination of the Structure of an Ordered Scheelite-Type: $\mathrm{Zr}_{3} \mathrm{GeO}_{8}$," Mater. Res. Bull., 19, 793-99 (1984).

${ }^{15} \mathrm{O}$. Muller and R. Roy, The Major Ternary Structural Families; pp. 87, 96 and 113. Springer-Verlag, New York/Berlin, 1974.

"P. Li, I-W. Chen, and J. E. Penner-Hahn, "X-ray Absorption Studies of Zirconia Polymorphs I. Characteristic Local Structures," Phys. Rev. B, 48 [14] 10063-73 (1993).

${ }^{17}$ JCPDS Card No. 36-1463.

${ }^{14} \mathrm{C}$. J. Howard, R. J. Hill, and B. E. Reichert, "Structures of the $\mathrm{ZrO}$, Polymorphs at Room Temperature by High-Resolution Neutron Powder Diffraction," Acta Crystallogr., B44, 116-20 (1988).

${ }^{19} \mathrm{~J}$. J. Rehr, J. Mustre de Leon, S. I. Zabinsky, and R. C. Albers, "Theoretica X-ray Absorption Fine Structure Standards," J. Am. Chem. Soc., 113, 5135 (1991).
${ }^{21} \mathrm{~B} . \mathrm{K}$. Teo, EXAFS: Basic Principles and Data Analysis, pp. 168. SpringerVerlag, New York, 1986.

${ }^{21}$ Y. Shimizugawa, H. Morikawa, F. Marumo, A. Nakajima, K. Urabe, and M. Normura, "Local Structure Around Ce Atoms in $\mathrm{CeO}_{2}$-Stabilized Tetragonal $\mathrm{ZrO}_{2}$, , J. Jpn. Ceram. Soc., 95, 1131-33 (1987).

${ }^{22} \mathrm{P}$. Li, "Local Atomic Structure and Phase Stability of Zirconia Polymorphs-Synchrotron X-ray Absorption Studies"; Ph.D. Thesis. Department of Materials Science and Engineering, University of Michigan, Ann Arbor, MI, 1992.

${ }^{23}$ G. Kaindl, G. Schmiester, E. V. Sampathkumaran, and P. Wachter, "Pressure-Induced in $\mathrm{L}_{\mathrm{III}} \mathrm{X}$-ray Absorption Near-Edge Structure of $\mathrm{CeO}_{2}$ and $\mathrm{CeF}_{4}$ : Relevance to $4 f$-Electron Structure," Phys. Rev. B, 38, 10174-177 (1988).

${ }^{24}$ J. Röhler, "X-ray Absorption and Emission Spectra"; pp. 536-38 in Handbook on the Physics and Chemistry of Rare Earths, Vol. 10. Edited by K. A. Gschreidner, Jr., L. Eyring, and S. Hüfner. Eisevier Science Publishers B.V., New York, 1987.

${ }^{25}$ R. D. Shannon, "Revised Effective Ionic Radii and Systematic Studies of Interatomic Distances in Halides and Chalcogenides," Acta Crystallogr., A32, $751-67$ (1976).

${ }^{26}$ D. Michel, L. Mazerolles, and M. P. Jorba, "Fracture of Metastable Tetragonal Zirconia Crystals,"J. Mater. Sci., 18, 2618 28 (1983).

${ }^{27}$ T.-S. Sheu, T.-Y. Tien, and I-W. Chen, "Cubic-to-Tetragonal $(t$ ') Transformation in Zirconia-containing Systems," J. Am. Ceram. Soc. 75 [5] 1108-16 (1992).

${ }^{28} \mathrm{P}$. Li, I-W. Chen, and J. E. Penner-Hahn, "X-ray Absorption Studies of Zirconia Polymorphs IIl. Static Distortion and Thermal Distortion," Phys. Rev. B, 48 [14] 10082-89 (1993).

${ }^{29}$ R. Zallen, The Physics of Amorphous Solids, Ch. 4, Wiley, New York, 1983.

${ }^{30} \mathrm{M}$. Yashima, K. Morimoto, N. Ishizawa, and M. Yoshimura, "Cubic-Tetragonal Transformations in the $\mathrm{ZrO}_{2}-\mathrm{CeO}_{2}$ System"; pp. $108-16$ in Science and Technology of Zirconia V. Edited by S. P. S. Badwal, M. J. Bannister, and R. H. J. Hannink. Techomic Publishing Co., Lancaster, PA, 1993.

${ }^{31}$ P. Duran, M. Gonzalez, C. Moure, J. R. Jurado, and C. Pascual, "A New Tentative Phase Equilibrium Diagram for the $\mathrm{ZrO}_{2}-\mathrm{CeO}_{2}$ System in Air," J. Mater. Sci., 25, 500I-5006 (1990). 